\title{
Future Directions in Physical Education \& Sport: Developing Fundamental Motor Competence in the Early Years Is Paramount to Lifelong Physical Activity
}

\author{
Jacqueline D. Goodway ${ }^{1}$, Ruri Famelia ${ }^{1} \&$ Syahrial Bakhtiar ${ }^{2}$ \\ ${ }^{1}$ The Ohio State University, USA \\ ${ }^{2}$ Universitas Negeri Padang, Indonesia \\ Correspondence: Jacqueline D. Goodway, Kinesiology Section, Department of Human Sciences, The Ohio State \\ University, 305 W.1 $7^{\text {th }}$ Ave, Columbus. OH. 43026, USA. E-mail: goodway.1@osu.edu
}

Received: January 16, 2014 Accepted: February 20, 2014 Online Published: February 28, 2014

doi:10.5539/ass.v10n5p44

URL: http://dx.doi.org/10.5539/ass.v10n5p44

\begin{abstract}
Worldwide obesity is a major concerned and has doubled since the 1980's. Overweight and obesity problems kill more people than underweight. Being overweight is not only limited to adults. More and more children below the age of five were overweight. As a result, the world is turning their attention to the importance of promoting physical activity at a younger age in an attempt to reduce obesity and chronic diseases later in life. Serious considerations need to be looked at especially in the area of physical activity and motor skills development among children and youth as these will determine their decision to remain physically active in later years. This article discusses the importance of physical activity for children in developing countries and provides some strategies in increasing fundamental motor skills among children.
\end{abstract}

Keywords: fundamental motor skills, children, obesity, physical activity

Lack of activity destroys the good condition of every human being, while movement and methodical physical exercise save it and preserve it.

Plato

\section{Worldwide Obesity Epidemic Drives Our Interest in Physical Activity}

There is a world-wide concern about the obesity levels of adult and children alike. Worldwide obesity has more than doubled since 1980. In 2008, 1.5 billion adults, 20 and older, were overweight and of these over 200 million men and nearly 300 million women were obese (World Health Organization [WHO], 2011a). The WHO (2011a) reports that $65 \%$ of the world's population live in countries where overweight and obesity kills more people than underweight, thus obesity is considered a major global health problem. This problem is not limited to adults and nearly 43 million children across the globe under the age of five were overweight in 2010. As a result, the world's attention has turned to the importance of promoting physical activity in an attempt to reduce obesity and chronic disease. Despite this, physical inactivity is now identified as the fourth leading risk factor for global mortality (WHO, 2011b). Physical inactivity levels are rising in many countries around the world with significant implications for the health of the world's population. The WHO has developed The Global Recommendations on Physical Activity for Heath (2011b) with the primary goal the prevention of chronic disease through physical activity at a population level. The main target audience for these recommendations is policy-makers at the national level, particularly in low- and middle-income countries such as Indonesia that don't have such recommendations.

It is clear we need to take a critical and developmental look at physical activity and motor skill development. Specifically we need to look at the role that physical education and youth sport engagement play, as this is the primary place where children and youth learn motor skills and learn to be active. There is a significant body of evidence that childhood and adolescent physical activity levels across the globe are down and this generation of children are less active and more overweight than other generations of children (WHO, 2011a; 2011b, 2011c). What is often not considered is the long term impact of such trends. In the USA it is anticipated that due to high 
levels of physical inactivity and childhood obesity, the current generation of children will be the first generation of children ever to have a lesser life expectancy than their parents.

One might assume that young children are not obese and highly active. However, even among preschoolers, obesity rates within the USA have doubled over the past few decades to a point where more than $10 \%$ of children ages 2-5 years are considered obese (Ogden \& Carroll, 2010). Concurrently physical activity levels have decreased in these young children (Pate, McIver, Dowda, Brown \& Addy, 2008; Reilly, 2010). Recent evidence suggests young children spend much of their daytime (often as much as $80 \%$ ) in sedentary behaviors and very little (as little as 3\%) of their day in health-enhancing moderate to vigorous physical activity (MVPA) (Pate et al, 2008; Reilly, 2010). Although boys tend to have higher physical activity levels than girls, both levels are low (Finn, Johannsen, \& Specker, 2002; Pate, et al., 2008). Additionally, as children get older their Moderate to Vigorous Physical Activity (MVPA) declines (Jackson et al., 2003).

"Screen time" has been identified as a major culprit of the decrease in physical activity. "Screen times" consists of children watching television \& DVDs, playing videogames, being on computers and the internet, and texting and interacting with their phones. It makes sense that children who have more screen time also have less physical activity (Durant, Thompson, Johnson \& Baranowski, 1996; Pate et al., 2008). It also is noteworthy that physical activity levels of children are influenced by the policies of the child care centers where they spend most of their time within westernized countries (Dowda, Pate, Trost, Almeida \& Sirard, 2004; Kaphingst \& Story, 2009).

It is important to note that disparities exist among children from different income levels, and obesity and physical inactivity are disproportionately higher among our low-income preschool children. According to the Pediatric Nutrition Surveillance System (PedNSS, 2009), nearly one third of 3.7 million low- income children within the USA (ages 2-4 years) were obese or overweight (CDC, 2011). Also, the lower the family income, the more likely it is that these children will be physically inactive (USDHHS, 1996, 2004). This is particularly true for African American and Hispanic children within the USA (USDHHS, 1996, 2004). I will speak more of these issues later in this paper.

Sadly the Indonesia statistics on obesity and inactivity reflect those of other countries around the world. In 2007 obesity rates for the under 5 year olds were $12 \%$ with 6 to 14 year olds having obesity rates at $10 \%$. By the time Indonesian youth are 15 years old $19 \%$ of youth are obese with over 43 million people in Indonesia overweight (Roemling \& Qain, 2012). Decreasing physical activity levels in the Indonesian population and increasing sedentary behaviors such television viewing and videogames are considered to be important determinants of the obesity epidemic in Indonesia (Roemling \& Qain, 2012).

These trends in childhood obesity and physical inactivity are of great concern from a public health and humanity stand point as they place children at greater risk for additional health problems such as diabetes and hypertension, as well as serving as a catalyst for social and behavioral issues that can be detrimental during the important early developmental years (Ward, 2010). As Plato recognized so many years ago, lack of physical activity destroys the human condition while some kind of physical engagement develops it. More than this, the children of our world have a right to engage in physical activity, active play, and sport as a natural part of their childhood. Ultimately they have a right to be physically literate. As a result of all of these data, national groups within the USA and other countries, as well as global groups like the WHO have highlighted the importance of systematic strategies to increase physical activity as a means to reduce childhood obesity and decrease chronic disease. The WHO recommends that "All sectors and all levels within governments, international partners, civil society, non-governmental organizations and the private sector have vital roles to play in shaping healthy environments and contributing to the promotion of physical activity" (WHO, 2011b).

Scholars in Indonesia have recognized that Indonesia must respond quickly stating that "the obesity pandemic in Indonesia will further increase in extent and severity unless significant remedial action is taken" (Roemling \& Qairn, 2012: 1011). They point to the importance of "early efforts on the prevention of obesity" (Usfar et al., 2010: 926) and "applying balance diet and physical activity as early as possible" (Usfar et al., 2010: 926-927). But few strategies are in place that meet these suggestions and we need to think carefully about the way forward for Indonesia.

Across the world we have worked hard to promote reading literacy in children and adults but what of physical literacy? How can we promote physical activity in childhood and what factors affect this? And what kinds of evidence-based programs will promote physical literacy, physical activity and motor competence within our younger children? In order to examine this we must look more closely at the emerging motor skills of children and the importance of physical education and sport as place where children learn to develop the skills, knowledge and 
attitudes for a lifetime of physical activity. Before we do this we will briefly look at the global and national recommendations for physical activity for children.

\section{The Importance of Daily Physical Activity}

Many Westernized countries provide national physical activity guidelines for children. However, I have chosen to list the WHO (2011b) guidelines as they reflect much of what is written around the world. The WHO (2011b) identifies "All children and youth should be physically active daily as part of play, games, sports, transportation, recreation, physical education, or planned exercise, in the context of family, school, and community activities. (page 18). Like the majority of other countries, 60 minutes of moderate-to-vigorous physical activity (MVPA) per day are recommended to help children and youth maintain a healthy cardiorespiratory and metabolic risk profile. (WHO, 2011b: 19). Additionally children should engage in muscle-strengthening activities 2 or 3 times per week to significantly improve muscular strength. This should be unstructured and part of play, such as playing on the playground equipment, or climbing trees etc.

The USA is the only place I know where national physical activity guidelines have been developed for children aged 0-5 years. These "Active Start" guidelines recommend that "All children birth to age 5 should engage in daily physical activity that promotes movement skillfulness and foundations of health-related fitness (NASPE, 2009). The guidelines are split into three age groups: infants (birth to onset of walking), toddlers (1-3 years), and preschoolers (3-5 years). For each age group there are five guidelines tied to promoting structured and unstructured physical activity, motor skill development, safe movement environments, and caregiver knowledge and engagement. I have summarized the preschool guidelines below but all of the guidelines, along with supporting documentation and movement suggestions, are very valuable and available from the National Association of Sport and Physical Education (2009):

Preschoolers should:

- $\quad$ accumulate at least 60 minutes of structured physical activity each day (guideline1).

- $\quad$ engage in at least 60 minutes -- and up to several hours -- of unstructured physical activity each day, and should not be sedentary for more than 60 minutes at a time, except when sleeping (guideline 2).

- be encouraged to develop competence in fundamental motor skills that will serve as the building blocks for future motor skillfulness and physical activity (guideline 3).

- have access to indoor and outdoor areas that meet or exceed recommended safety standards for performing large-muscle activities (guideline 4).

- Caregivers and parents in charge of preschoolers' health and well-being are responsible for understanding the importance of physical activity and for promoting movement skills by providing opportunities for structured and unstructured physical activity (guideline 5).

*Reprinted with the permission of the National Association of Sport and Physical Education

\section{Developing the Physically Literature Child}

Physical literacy can be described as the "motivation, confidence, physical competence, understanding \& knowledge to maintain physical activity at an individually appropriate level, throughout life" (Whitehead, 2010). Developing movement competence during the early years is paramount and if children have insufficient opportunities to develop their physical literacy it can lead to devastating life consequences (Whitehead, 2010). Like the WHO, I believe all children should be provided with the necessary support and resources they need to develop physical literacy early in life. The development of motor competence, and opportunities to be physically active are an important part of being physically literate. However, physical literacy is a much more than this and I refer you to Whitehead (2010) for an extensive discussion of the concept. In terms of this paper we will first look at the importance of fundamental motor skills (FMS) in the engagement of physical activity and sport. As part of this section we will look at gender differences in FMS development and also the developmental delays that exist in FMS development of our most vulnerable and poor children. We will then look to kinds of motor skill programs that have had impact on FMS competence and physical activity.

\section{The Importance of Fundamental Motor Skills}

One of the most critical skill sets children need to begin to acquire in early childhood is competence in FMS (Gallahue, Ozmun \& Goodway, 2012). FMS are the building blocks to future physical activities and sport and are the movement equivalent to the ABCs in reading literacy. FMS consist of two groups of skills including locomotor and manipulation skills. Locomotor skills are skills such as running, jumping, hopping, leaping, sliding, galloping and skipping, in other words a child moves his/her body from one point to another. 
Manipulation skills (also called object control skills) are skills such as throwing, catching, kicking, punting, striking, rolling, and bouncing, they involve the manipulation of an object like a ball or bat (Gallahue et al., 2012). Motor development scholars often use a mountain as a metaphor for the acquisition of motor skills, that is children need to scale the mountain of motor development. A number of prominent models of motor development suggest that FMS are critical and the foundation (Gallahue et al., 2012; Seefeldt, 1982) or basecamp (Clark \& Metcalfe, 2003) to the mountain of motor development.

\subsection{Sequential Model of Motor Development.}

Seefeldt (1980) proposed one of the earliest models in motor development shaped like a mountain or pyramid. In this four phase sequential approach, the "Reflexes and Reactions" of infancy are at the bottom of the pyramid and serve as the foundation for all future movement skills. Built upon this foundation the young child begins to develop FMS including locomotor and manipulation skills such as running and throwing. The unique part to this model is the notion of a "Proficiency Barrier" after FMS. Seefledt suggested that the development of basic competence in FMS is a prerequisite for future sports and games and FMS are the movement equivalent of the ABCs. That is, a child who cannot run and throw and catch with basic competency is unlikely to engage successfully in sports where these skills are needed. Seefeldt believed the development of basic FMS competence in early childhood years was necessary if the child were to move to higher levels of the mountain and engage in sports, games, and dances with competency. Acquiring competency in FMS allows children to move through to the last two phases of the model, "Transitional Skills" (e.g. lead up sports such as small-sided soccer, t-ball) and "Specific Sports Skills and Dances" often conducted during middle childhood and adolescence. Thus, this model highlights the importance of the early childhood years in developing the FMS movement competency necessary for lifelong participation in sports and other physical activities. In other words, if children do not develop competence in FMS, they will have little success in engaging in youth sports.

\subsection{Mountain of Motor Development Model}

Clark and Metcalfe (2002) developed a six-phase "Mountain of Motor Development" model as a metaphorical way to understand the development of motor skills across the lifespan. Their model is based on the dynamical systems framework of multiply-developing systems that self-organize in non-linear ways. Clark and Metcalfe proposed that progression up the mountain was specific to an individual's experiences and the constraints they experienced along the route. Similar to Seefeltd, the first two phases of this model consisted of the "Reflexive" period and the "Preadapted" period, that is reflexes and reactions shift to voluntary movements ending in the onset of independent walking and self-feeding behaviors. The third phase is the "fundamental movement" phase of the model. Like the other model, these FMS are considered key building blocks to later movement. Clark \& Metcalfe referred to FMS as the "base camp" of the mountain and provides the basis for later "motor skillfulness" (p. 17). Further up the mountain children begin to apply FMS to "Context Specific" environments such as throwing can be applied in cricket or rugby and ultimately with appropriate experiences, children may develop "Skillfulness" (the top of the mountain). Unlike other models, Clark \& Metcalfe recognize that no individual becomes skillful across a broad variety of activities. For example a highly proficient gymnast may not be a good volleyball player. Thus, the mountain has different "peaks" (different sports or activities) with each peak being of a different height, reflecting the notion that individuals will have varying levels of skillfulness across different activities. Clark and Metcalfe also highlight the importance of early childhood in developing a broad base of FMS by about age seven years. If these skills are developed, children are well positioned from their "base camp" on the mountain of motor development to navigate many different mountain peaks (sports and physical activities) given sufficient and appropriate experiences. That is, FMS are critical for the engagement in later youth sport and lifetime physical activity.

\subsection{Hour Glass Model of Motor Development}

Gallahue, Ozmun and Goodway (2012) used an "hour glass" to describe the processes of motor development. The falling sands into the hour glass represent the development of motor skills as they are influenced by both heredity (genetics) and environment. As the sands land in the bottom of the hour glass, they build the phases and stages of motor development across the lifespan similar to the two models above. Like the other models above, the reflexive movement phase comes first and is followed by the rudimentary movement phase, where the infant develops a variety of basic movement patterns such as control of the head, and trunk, controlled grasping, and proficiency in creeping and crawling. Children then shift to the fundamental movement phase during the early childhood/primary school years. This is the period of time where children experiment and explore their movement potential in a variety of FMS that form the building blocks for the fifth and final phase. In the final phase, specialized movement skill phase, more complex movement skills such as those in sports and games are 
refined and mastered. Variability in the rate and extent of skill acquisition is determined by a wide variety of environmental as well as biological factors.

\subsection{Spiral of Engagement-Disengagement Model}

Recently David Stodden and I along with other colleagues developed a spiral model of engagement-disengagement in physical activity (Stodden et al., 2008; Stodden \& Goodway, 2007). This model suggests that there is dynamic and reciprocal relationship between FMS competence and physical activity behaviors across the lifespan. In the early years opportunities to be physical active may drive the development of motor skill competence in the form of FMS acquisition. Differences in initial levels of FMS development are due to many factors including immediate environment, structured physical education, socioeconomic status, parental influences, climate, etc. Thus, we hypothesize that young children will demonstrate variable levels of physical activity and FMS.

As children transition to middle childhood and adolescence, we believe the relationship between physical activity and motor skill competence becomes more important and will strengthen. During middle childhood and adolescence, higher levels of motor skill competence will offer greater options to engage in various physical activities, sports, and games. We expect more highly skilled motor competent children will self-select higher levels of physical activity. Across time their perceived motor competence will be strong (as they are good at sport and know it) and their fitness levels will also be good. The interaction of all of these factors results in a positive spiral of engagement in sport and physical activity with these children being highly engaged in sport and activity.

The opposite is true for our less skillful (not motor competent) children. These less skillful children will engage in lower levels of physical activity. Across time they look around at their peers and know they are not motor competent and thus their perceived motor competence is low (they are not good at sport and know it) and because they are less active, their fitness levels will also be low. The interaction of all of these factors results in a negative spiral of engagement in sport and physical activity. Given a choice, these children will be sedentary and not elect to engage in sport or physical activity. As children move from primary school into the adolescent years the result of the positive and negative spirals of (dis)engagement is a marked difference in the activity levels and sport engagement of children. Those children who are in the positive spiral of engagement are active, engaged regularly in sport, see themselves as "movers" and hopefully on the path to a healthy adulthood. However, those children who are in the negative spiral of engagement are sedentary, not engaged in sport, and most likely overweight or obese. These children have a greater likelihood they will be unhealthy as adults with higher rates of diabetes and heart disease.

In conclusion, these four models highlight the importance of FMS development during the early childhood years and how FMS competence is critical to lifelong physical activity and participation in youth sport. But how do these FMS develop? And what can we do to promote motor competence in FMS? In the next part of the paper I hope to answer some of these questions.

\section{Sequential Development of Fundamental Motor Skills}

As we look out at the playground and watch young children play it may seem that children run, throw and jump in the same manner. But a closer observation of their skills will reveal that even children of the same age look very different in the way they perform motor skills (Gallahue et al., 2012). A small child might show a stationary "chop throw", while a girl steps and throws with the same hand and foot, and another boy throws forcefully with wind-up of the arm, and arm-leg opposition. We know from the motor development literature that children don't just naturally perform FMS with proficiency; they typically progress through a common sequence of movements that start with inefficient and unstable patterns of performance. With sufficient practice and feedback children will develop more proficient patterns of performance and greater abilities to consistently apply these skills to sports and games (Gallahue et al., 2012; Stodden et al., 2008; Stodden \& Goodway, 2007). Research in motor development has identified developmental sequences for ten FMS (Seefeldt \& Haubenstricker, 1982) with anywhere between 3 and 5 stages of development per skill. Table 1 and 2 describe these developmental sequences (for a more detailed description see Gallahue, et al., 2012). Knowledge of these developmental sequences is valuable as it can inform the teacher about the kinds of physical activities that are developmentally appropriate for a given child. These stages can also serve as an assessment of a child's emerging FMS competence. 


\section{Gender Differences in FMS}

Both girls and boys pass through the same sequence of motor skill development. However, gender differences can be found in FMS performance starting as young as the preschool years (Seefeldt \& Haubenstricker, 1982; Thomas \& French, 1985). Both boys and girls have similarities in locomotor skills such as running and jumping; however, boys regularly outperform girls in manipulation skills (Seefeldt \& Haubenstricker, 1982; Goodway, Robinson, \& Crowe, 2010). It is not clear from the developmental literature why this might be but some scholars have pointed to biological factors such as strength or sociocultural factors such as unequal opportunities to be active, modeling, and feedback (Thomas \& French, 1985). Williams et al. (1996) suggested that gender differences are present because boys practice these skills more than girls, which leads boys to be more proficient movers. Gender differences in manipulation skills raise concerns that girls will not have the necessary skills to engage in youth sport.

These gender differences are found in children as young as four years of age and specifically in our most poor children. Recent data on the FMS of low income preschool children found differential gender effects between locomotor and manipulative skills across ethnicity (African American/Hispanic) and region within the USA (Goodway, Robinson, \& Crowe, 2010). My colleagues and I have consistently found there were no gender differences in locomotor skills but boys had significantly better manipulation skills than girls (Goodway \& Branta, 2003; Goodway, Crowe, \& Ward, 2003; Goodway, et al., 2010; Robinson \& Goodway, 2009). It is not clear from the research literature why this is so, but for the past decade these findings have remained consistent across geographic region and ethnicity. Locomotor skills are considered to be more phylogenetic (based upon neurological/genetic factors) than manipulative skills. The opportunity to practice locomotor skills requires available space to run, gallop and jump but does not require equipment. Thus, it may be that girls and boys had equal opportunities to engage in locomotor skills within their respective communities. In contrast, potential explanations as to gender differences in manipulation skills may be differential access to equipment, role models, and motivation to engage in motor skills. Anecdotal comments from my research with preschoolers suggest that boys typically come to the testing environment with a greater familiarity of the vocabulary and equipment associated with manipulation skill performance than girls, perhaps suggesting prior experience plays a role in these findings (Goodway et al., 2010). Other alternative explanations for gender differences in FMS may be that girls tend to be driven by more social factors (e.g. pleasing the teacher, receiving verbal encouragement, and smiles) in the learning environment; while boys are more motivated by competition and the product of the performance (Garcia, 1994; Garcia \& Garcia, 2002).

\section{Disadvantaged Preschoolers Demonstrate Developmental Delays in FMS}

Establishing habits that foster forming proficient levels of FMS and healthy levels of physical fitness are critical events that take place during the early childhood years. However, there are disparities in the opportunity to do this. A growing body of research shows that young children who come from disadvantaged and poor environments show significant developmental delays in their FMS, including locomotor $\left(10^{\text {th }}-17^{\text {th }}\right.$ percentile $)$ and manipulation $\left(16^{\text {th }}\right.$ percentile) skills (Goodway \& Branta, 2003; Goodway, Crowe \& Ward, 2003; Goodway et al., 2010; Hamilton et al., 1999; Robinson \& Goodway, 2009). This has been found true for African American and Hispanic children, across geographic region, and urban and rural environments (Goodway \& Branta, 2003; Goodway et al., 2003; Goodway et al., 2010; Hamilton et al., 1999; Robinson \& Goodway, 2009).

In a recent large-scale study of the FMS $(N=275)$ children from Head Start, $85 \%$ to $92 \%$ of all children tested were developmentally delayed (Goodway et al., 2010). Like the findings above, locomotor skills of the girls and boys were the same (delayed), but the girls had significantly worse manipulation skills than boys. This is of particular concern considering the boys' skills were delayed but the girls were even more delayed (Goodway et al., 2010). It is no wonder that by adolescence, girls from these populations have some of the lowest physical activity rates of all children and youth (USDHH, 1996; 2004). It is clear from the research evidence that a sizeable number of disadvantaged preschool children are delayed in their FMS and require motor skill intervention to remediate the developmental delays reported.

Little evidence is available to explain why such delays exist in the motor skills of disadvantaged children. However, some qualitative work I have conducted with a colleague (Goodway \& Smith, 2005) has shown that in "In disadvantaged urban communities fundamental barriers exist which obstruct a child's ability to engage in physical activity \& develop motor competence and physical literacy." Factors that have been identified are: the outside environment; inside environment; influence of poverty; cultural values \& beliefs, and; the nature of family dynamics. Children in at risk communities have no-where safe to play. The parks and streets are full of gangs, drugs and guns and few children have back yards in which to play. The inside housing environment 
typically has large numbers of children and adults in a small space, thus the primary strategy is to turn on the television or video game and encourage sedentary behaviors of children as a means to control the chaos in the house. Poverty is an overriding factor that influences all aspects of the child's upbringing from a Mother who is never around as she working several minimum pay jobs to provide for her children to the fact there is no money available to sign children up for youth sports. Lack of transportation is often another barrier in accessing sport and activity experiences for children. Many of the parents of our disadvantaged children know that physical activity is important, value it as an important part of their children's upbringing, but are incapable of accessing sport and physical activity due to the many barriers in their environments. Thus, policy makers need to look at ways in which we can provide physical activity experiences to our young underserved children and enact local, regional, and national policies that will give all disadvantaged families access to sport and physical activity in their lives.

There is little evidence in Indonesia regarding FMS, but the research evidence that does exist suggests Indonesian demonstrate developmental delays in FMS (Bakhtiar, 1999; 2011). A study of 720 Indonesian elementary school students in grades 4-6 found that the children were at beginning levels in jumping, running, catching, and balancing. This is a major concern as this age of children should have developed competency in FMS by this age. Thus, it is clear, that like other parts of the world, that motor skill interventions are needed in Indonesian elementary schools and preschools.

\section{Effects of Motor Skill Instruction on the FMS of Disadvantaged Children}

A growing number of scholars, of which I am one, have begun to examine the influence of motor skill intervention on the FMS of disadvantaged preschool children. At the Ohio State University my research team and I have developed a motor skill intervention called SKIP, Successful Kinesthetic Instruction for Preschoolers with over 20 years of research driving the content of the curriculum. The SKIP program is a FMS and physical activity program designed for young children (preschool to $3^{\text {rd }}$ grade). The goals of SKIP are to promote FMS competence and physical fitness, improve individual perceptions of motor competence, engage in and increase the amount of structured and unstructured MVPA (moderate to vigorous physical activity), develop an understanding of the body's response to movement and the importance of physical activity as part of an active and healthy lifestyle. The curriculum is made-up of locomotor and object control skills along with non-locomotor skills, movement concepts and health-related fitness. One of the key concepts of SKIP is individualized, differentiated instruction where the tasks and feedback are aligned with each child's unique developmental level. Child success is promoted by ensuring that there is an array of developmental tasks so that each child can be challenged at an appropriate level of challenge for his/her development. We focus on a child's understanding of their own emerging kinesthesis allowing children to focus on the proprioceptive feedback his/her body provides. We call this "muscle munchkins" to our young children and tell the children to listen carefully for their muscle munchkins to talk to them. Another core concept is a child's self evaluation of his improvement and that task persistence will to movement acquisition and task success.

Overall, studies on motor skill interventions such as SKIP show that when motorically delayed preschool children received well designed structured motor skill instruction, significant improvements in their FMS resulted which to remediated these delays (Goodway \& Branta, 2003; Goodway et al., 2003; Hamilton et al., 1999; Martin, Rudisill, \& Hastie, 2009; Robinson \& Goodway, 2009). The timeframe of these programs has typically been somewhere between 8 to 12 weeks (16 to 24 lessons) with $30-45$ minutes per session. The majority of these programs have focused on manipulation skills although some have also included locomotor skills. A variety of instructional approaches have been utilized to deliver the motor skill interventions including: 1) direct instruction (Connor-Kuntz \& Dummer, 1996; Goodway \& Branta, 2003; Goodway et al., 2003); 2) mastery motivational climate (Martin, et al., 2009; Robinson \& Goodway, 2009; Valentini \& Rudisill, 2004) and 3) parents as teachers (Hamilton et al., 1999).

"Direct instruction" involves a teacher-led approach where the teacher instructs each element of the lesson, clearly describes and demonstrates the task to be performed, and the children respond accordingly. "Mastery motivational climate" (MMC) involves a more student-centered approach in which the teacher plans the lesson elements, but the children are allowed to choose the tasks and activities based upon their preferences (Valentini \& Rudisill, 2004; Robinson \& Goodway, 2009). MMC lessons are planned around manipulating six "TARGET" structures within the lesson where the acronym TARGET stands for: Task, Authority, Reward, Grouping, Evaluation, Time (see Valentini, Rudisill \& Goodway, 1999 for a detailed explanation). The rationale behind the MMC approach is that the instructional climate promotes students' motivation to engage in tasks and regulate their own pace of learning. "Parents as teachers" trains parents to instruct their child on FMS while a lead teacher develops the lesson plans and acts as the facilitator during lesson implementation (Hamilton, et al. 1999). 
All the motor skill intervention approaches identified above have been successful in significantly impacting the FMS competence of disadvantaged preschoolers. Many of these program shave been provided at the state-funded preschool programs in which the children are enrolled. In all of these interventions high quality instruction was provided along with maximum opportunities for practice. Sufficient equipment was available and tasks were individualized to the child's own developmental needs. In many cases, the developmental changes were substantial going from the $10^{\text {th }}-15^{\text {th }}$ percentile to the $60^{\text {th }}-80^{\text {th }}$ (Goodway \& Branta, 2003; Goodway et al., 2003; Goodway et al., 2010; Hamilton et al., 1999; Robinson \& Goodway, 2009).

Some general conclusions may be drawn from the studies identified above: 1) disadvantaged preschool children are delayed in their motor skills and in need of intervention; 2) when provided with structured, developmentally appropriate motor instruction children can make significant and often large gains in their FMS remediating their prior delays, and 3) the children in the control groups who received the typical preschool curricula where physical activity opportunities were often non-facilitated and play-based, resulted in no improvements to FMS development. In other words, current educational practice in these programs is not meeting the needs of these children. In addition the young children who received the SKIP curriculum not only improved their actual motor competence but also improved their perceptions of motor competence whereas the control children stayed the same. This is of major long term concern as the children will not have the requisite skills to be physically active as adolescents and adults, and it is this very demographic (poor, African American and Hispanic) that goes on to demonstrate the lowest levels of physical activity and the highest levels of obesity as adolescents and adults (USDHHS, 1996; 2004).

\section{Implications to Indonesia}

As I reflect on the data above I have considered the implications to physical education and sport in Indonesia. The following are a number of implications:

\subsection{Develop National Physical Activity Guidelines for Preschool and Elementary-Aged Children}

There is a need to develop physical activity guidelines for Indonesian children in preschools and elementary schools. Earlier above I shared the guidelines for the USA which consisted of focusing on FMS competence and 60 minutes or more of structured physical activity per day. For the preschool child we also need to recognize the important role of their caregivers and ensure such people are educated in motor development and motor skill programs. Additionally we should ensure there are safe places to play. For the school-aged child there we should also highlight FMS competence and 60 minutes of MVPA per day as well as decreasing sedentary behaviors such as screen time.

\subsection{Prepare Physical Education Teachers to Teach Children from Preschool to Secondary School}

Across the world there is little attention paid to preparation of physical educators in teaching our preschool and early elementary children. Our teacher training programs and elementary curriculum focus on team sports. We need to ensure specialist physical education teachers are provided in all preschools and that as we train elementary PE teacher's, they are taught to differentiate instruction and curriculum that is developmentally appropriate for the young child.

\subsection{Implementation of Evidence-Based Early Years Physical Education Curriculum}

Often the programs that are implemented in schools are not based upon empirical evidence. We need to ensure that evidence-based programs such as SKIP are implemented in our schools so we are guaranteed as to the effectiveness of such programs.

\subsection{Develop Specific Strategies to Engage Girls and Bring about Actual and Perceived Motor Competence Outcomes}

Girls constitute a particularly vulnerable population. Girls have worse object control skills than boys and in Indonesia women are much more likely to be obese than men. We need to develop specific pedagogical practices and programs that engage and motivate girls to achieve motor competence. Often are girls get lost in the motor environment and subsequently drop out of activity and sport at higher levels than boys.

\subsection{Develop Specific Strategies to Promote Perceptions of Motor Competence}

The evidence on the importance of motor competence is overwhelming. As children shift from childhood to adolescence, if they have low perceptions of motor competence they will be inactive and disengaged from sport. We need to capitalize on young children's inflated sense of motor competence in the early years using this as a valuable resource to keep children engaged in our motor settings. However, as children get older and more capable of evaluation it will be actual competence that will drive a child's perceived motor competence. As we 
work with our children we should not compare children's performance against each rather, rather get the child to focus on his/her individual journey up the mountain of motor development.

\subsection{Highlight the Importance of a "Sport For All" Health-Based Development Approach to the Sports Systems} in Indonesia

Youth sport is a huge part of the lives of many children around the globe and is the primary place in childhood where children engage in physical activity. Historically, one of the main philosophical approaches to youth sport in Indonesia is the elite competitive sport approach. However, as a result of the increase in childhood obesity and physical inactivity I believe a second approach needs much greater consideration and emphasis, the public health and youth development approach. The goal of the elite competitive sports model is to produce elite level, competitive athletes. In this approach the idea is to recruit large masses of children into the sport in order to be able to identify and nurture the most talented young athletes. The focus of this approach is high level skill development and focusing on those children who are most skilled. Often, a single sport approach is necessitated and youth sport athletes engage in only one sport with intense training to yield maximal sport performance. Those who get to compete and play on a team are the children with most skill and the less skilled child is either cut from the team or benched. I believe the more important approach to youth sport is a public health and youth development approach. In this capacity, the goal of youth sport is to provide children with the skills, knowledge and attitudes that will result in a desire to engage in regular sports participation and physical activity across childhood and into adulthood. In conjunction with this approach those in the youth development area utilize sport as medium to focus on the development of positive character traits in the child such as honesty, effort, sportspersonship, and task persistence. Additionally, this approach promotes life-skills such as communication, teamwork and conflict resolution through positive sports experiences. With this approach the goal would be to enroll children early in a basic motor competence program, then provide them access to a variety of sports where they develop motor and social/affective skills to keep them engaged in sport as they transition across childhood into adolescence and adulthood. That is, use sport as a tool or medium to meet other goals. Mass participation is key, and engagement in sport by all children, even those from our poorest communities is paramount.

\section{Conclusions}

There are many challenges facing the children of Indonesia, but overweight/obesity and physical inactivity are two of the major challenges. More than half (65\%) of the world's population live in countries where overweight and obesity kills more people than underweight and physical inactivity is now identified as the fourth leading risk factor for global mortality (WHO, 2011a, 2011b). The development of fundamental motor skill competence is critical if children are to be physically active and to engage in youth sports. Yet many of our poorest children start the early childhood years with developmental delays in motor skills. Access to safe places to play, be physically active, and engage in youth sports is a common problem in our cities. It is clear Indonesia needs to act and develop policies and environments that promote physical activity and youth sports engagement for all children.

\section{References}

Bakhtiar, S. (1999). Kemampuan Gerak Dasar Pelajar Sekolah Dasar Negeri Kota Padang (The report of Research Result). Padang: IKIP Padang.

Centers for Disease Control. (2011). Obesity among low-income preschool children. Retrieved March 5, 2012, from http://www.cdc.gov/obesity/downloads/PedNSSFactSheet.pdf

Clark, J. E., \& Metcalfe, J. S. (2002). The mountain of motor development: A metaphor. In J. E. Clark, \& J. H. Humphrey (Eds.), Motor Development: Research and Review (Vol. 2, pp. 163-187). Reston, VA: NASPE Publications.

Conner-Kuntz, F., \& Dummer, G. (1996). Teaching across the curriculum: Language-enriched physical education for preschool children. Adapted Physical Activity Quarterly, 13, 302-315.

Dowda, M., Pate, R. R., Trost, S. G., Almeida, M. J., \& Sirard, J. R. (2004). Influences of preschool policies and practices on children's physical activity. Journal of Community Health, 29(3), 183-196. http://dx.doi.org/10.1023/B:JOHE.0000022025.77294.af

Durant, R. H., Thompson, W. O., Johnson, M., \& Baranowski, T. (1996). The relationshipamong television watching, physical activity and body composition of 5 or 6 year old children. Pediatric Exercise Science, 8, 15-26.

Finn, K., Johannsen N., \& Specker, B. (2002). Factors associated with physical activity in preschool children. 
Pediatrics, 140, 81-85. http://dx.doi.org/10.1067/mpd.2002.120693

Gallahue, D. L., Ozmun, J. C., \& Goodway, J. D. (2012). Understanding Motor Development: Infants, children, adolescent and adults (7th ed.). Boston: McGraw-Hill.

Garcia, C. (1994). Gender differences in young children's interaction when learning fundamental motor skills. Research Quarterly for Exercise \& Sport, 65, 213-225. http://dx.doi.org/10.1080/02701367.1994.10607622

Garcia, C., \& Garcia, L. (2002). Examining developmental changes in throwing. In J. E. Clark \& J. H. Humphrey (Eds.), Motor Development: Research and Review (Vol. 2, pp. 62-95). Reston, VA: NASPE Publications.

Goodway, J. D., \& Branta, C. F. (2003). Influence of a motor skill intervention on fundamental motor skill development of disadvantaged preschool children. Research Quarterly for Exercise \& Sport, 74, 36-47. http://dx.doi.org/10.1080/02701367.2003.10609062

Goodway, J. D., \& Smith, D. W. (2005). Keeping all children healthy: Challenges to leading an active lifestyle for preschool children qualifying for at-risk programs. Family \& Community Health, 28, 142-155. http://dx.doi.org/10.1097/00003727-200504000-00006

Goodway, J. D., Crowe, H., \& Ward, P. (2003). Effects of motor skill instruction on fundamental motor skill development. Adapted Physical Activity Quarterly, 20, 298-314.

Goodway, J. D., Robinson, L. E., \& Crowe, H. (2010). Developmental delays in fundamental motor skill development of ethnically diverse and disadvantaged preschoolers. Research Quarterly for Exercise \& Sport, 81, 17-25. http://dx.doi.org/10.1080/02701367.2010.10599624

Gusril. (2003). Faktor-faktor yang mempengaruhi kemampuan motoric siswa sekolah dasar Negeri Kotamadya Padang (Disertation). Jakarta: PPS Universitas Negeri Jakarta.

Hamilton, M., Goodway, J. D., \& Haubenstricker, J. (1999). Parent-assisted instruction in a motor skill program for at-risk preschool children. Adapted Physical Activity Quarterly, 16, 415-426.

Jackson, D. M., Reilly, J. J., Kelly, L. A., Montgomery, C., Grant, S., \& Paton, J. Y. (2003). Objectively measured physical activity in a representative sample of 3 to 4 year old children. Obesity Research, 11(3), 420-425. http://dx.doi.org/10.1038/oby.2003.57

Kaphingst, K. M., \& Story, M. (2009). Child care as an untapped setting for obesity prevention: State child care licensing regulations related to nutrition, physical activity, and media use for preschool-aged children in the United States. Preventing Chronic Disease: Public health research, practice, and policy, 6(1), 1-13.

Martin, E. H., Rudisill, M. E., \& Hastie, P. (2009). The effectiveness of a mastery motivational climate motor skill intervention in a naturalistic physical education setting. Physical Education and Sport Pedagogy, 14, 227-240. http://dx.doi.org/10.1080/17408980801974952

National Association for Sport and Physical Education. (2009). Active Start: A statement of physical activity guidelines for children birth to five years (2nd ed.). Oxon Hill, MD: AAHPERD Publications.

Ogden, C., \& Carroll, M. (2010). Prevalence of obesity among children and adolescents: United States, trends 1963-1965 through 2007-2008. NCHS Health E-Stats. Retrieved from http://www.cdc.gov/nchs/data/hestat/obesity_child_07_08/obesity_child_07_08.htm

Pate, R. R., McIver, K., Dowda, M., Brown, W. H., \& Addy, C. (2008). Directly observed physical activity levels in preschool children. Journal of School Health, 78(8), 434-444. http://dx.doi.org/10.1111/j.1746-1561.2008.00327.x

Reilly, J. J. (2010). Low levels of objectively measured physical activity in preschoolers in child care. Medicine \& Science in Sports \& Exercise, 42, 502-507. http://dx.doi.org/10.1249/MSS.0b013e3181cea100

Robinson, L. E., \& Goodway, J. D. (2009). Instructional climates in preschool children who are at risk. Part I: object control skill development. Research Quarterly for Exercise \& Sport, 80, 533-542.

Seefeldt, V. (1980). The concepts of readiness applied to motor skill acquisition. In R. A. Magill, M. J. Ash, \& F. L. Smoll (Eds.), Children in Sport. Champaign, IL: Human Kinetics.

Seefeldt, V., \& Haubenstricker, J. (1982). Patterns, phases, or stages: An analytic model for the study of developmental movement. In J. A. S. Kelso, \& J. E. Clark (Eds.), The Development of Movement Control and Co-Ordination (pp. 309-318). New York: Wiley.

Stodden, D. F., \& Goodway, J. D. (2007). The dynamic association between motor skill development and 
physical activity. Journal of Physical Education, Recreation and Dance, 78, 33-49. http://dx.doi.org/10.1080/07303084.2007.10598077

Stodden, D. F., Goodway, J. D., Langendorfer, S. J., Roberton, M. A., Rudisill, M. E, Garcia, C., \& Garcia L. E. (2008). A Developmental perspective on the role of motor skill competence in physical activity: An emergent relationship. Quest, 60, 290-306. http://dx.doi.org/10.1080/00336297.2008.10483582

Thomas, J. R., \& French, K. E. (1985). Gender differences across age in motor performance: A meta-analysis. Psychological Bulletin, 98, 260-282. http://dx.doi.org/10.1037/0033-2909.98.2.260

U.S. Department of Health and Human Services. (1996). Physical activity and health: A report of the Surgeon General. Atlanta, GA: Center for Disease Control and Prevention.

U.S. Department of Health and Human Services (USDHHS). (2004). Physical Activity and Fitness. Retrieved from http://www.healthypeople.gov/data/2010prog/focus22/PhysicalFitnessPR.pdf

Valentini, N. C., \& Rudisill, M. E. (2004). An inclusive mastery climate intervention and the motor skill development of children with and without disabilities. Adapted Physical Activity Quarterly, 21, 330-347.

Valentini, N. C., Rudisill, M., \& Goodway, J. D. (1999). Incorporating a mastery climate into physical education: It's developmentally appropriate. Journal of Physical Education Recreation and Dance, 7, 28-32. http://dx.doi.org/10.1080/07303084.1999.10605683

Ward, D. S., Vaughn, A., McWilliams, C., \& Hales, D. (2010). Interventions for increasing physical activity at child care. Medicine \& Science in Sports \& Exercise, 42, 526-534. http://dx.doi.org/10.1249/MSS.0b013e3181cea406

Whitehead, M. E. (2010). Physical literacy: Throughout the life course. Routledge: London \& New York.

Williams, K., Haywood, K. M., \& Painter, M. A. (1996). Environmental versus biological influences on the on gender differences in the overarm throw for force: Dominant and non-dominant arm throws. Women in Sport and Physical Activity, 5, 29-48.

World Health Organization. (2011a). Obesity and overweight factsheet. Retrieved March 15th, 2012, from http://www.who.int/mediacentre/factsheets/fs311/en/index.html

World Health Organization. (2011b). Global recommendations on physical activity for health. Retrieved March 17, 2012, from http://www.who.int/dietphysicalactivity/leaflet-physical-activity-recommendations.pdf

World Health Organization. (2011c). 10 facts on physical activity. Retrieved March 5th, 2012, from http://www.who.int/features/factfiles/physical_activity/en/

\section{Copyrights}

Copyright for this article is retained by the author(s), with first publication rights granted to the journal.

This is an open-access article distributed under the terms and conditions of the Creative Commons Attribution license (http://creativecommons.org/licenses/by/3.0/). 